\title{
Impactos ambientais da degradação do solo provocados pela extração da argila para indústria cerâmica em São Miguel do Guamá-PA
}

\author{
Environmental impacts of soil degradation caused by the extraction of clay for the ceramic industry \\ in São Miguel do Guamá-PA \\ Impactos ambientales de la degradación del suelo causada por la extracción de arcillas para la \\ industria cerámica en São Miguel do Guamá-PA
}

Recebido: 03/08/2021 | Revisado: 09/08/2021 | Aceito: 17/08/2021 | Publicado: 19/08/2021

Felipe Daniel Souza Cavalcante

ORCID: https://orcid.org/0000-0002-3975-8922

Universidade do Estado do Pará, Brasil E-mail: daniel_souzac@hotmail.com

João Paulo Sousa da Silva

ORCID: https://orcid.org/0000-0001-7174-0389 Universidade do Estado do Pará, Brasil E-mail: joaopaulojoao482@gmail.com

Carlos Otávio Rodrigues dos Santos

ORCID: https://orcid.org/0000-0002-4457-1337 Universidade do Estado do Pará, Brasil E-mail: otavio.eng.amb@gmail.com

Letícia Picanço da Silva

ORCID: https://orcid.org/0000-0003-1744-003X Universidade do Estado do Pará, Brasil E-mail: leticiapicanco@hotmail.com

Camila Nascimento Alves

ORCID: https://orcid.org/0000-0001-5093-7078 Universidade do Estado do Pará, Brasil E-mail: Camila.alves@uepa.br

Rodolfo Pereira Brito

ORCID: https://orcid.org/0000-0002-0393-5181 Universidade do Estado do Pará, Brasil E-mail: professor@pereirabrito.com

\begin{abstract}
Resumo
A argila é um mineral proveniente da desagregação de rochas que contém feldspato, através da ação do intemperismo. Este mineral é de grande importância para o segmento de construção civil, pois, através dele se obtém tijolo e telhas. O uso e exploração intensivos deste recursos natural tem degradado o meio ambiente de forma significativa, e gera impactos ambientais como, por exemplo, alteração da paisagem, formação de lagoas, alteração da topografia, alteração na estrutura e biologia do solo, etc. O município de São Miguel do Guamá é um polo de produção cerâmica, e suas áreas de extração já apresentam diversos impactos negativos como o assoreamento dos leitos do rios, formação de lagoas, alteração da topografia, entre outros. Dessa forma, a presente pesquisa visa fazer uma Matriz de Avaliação de Impactos Ambientais - MAIA, relacionar as medidas de mitigação desses impactos, e fazer uma análise química nos parâmetros pH, Fósforo, Potássio, Nitrogênio, Relação Carbono x Nitrogênio, e Carbono Orgânico; do solo (Latossolo Amarelo), no local de estudo. As amostras foram coletadas utilizando-se de três trincheiras, com espessura 50x50 cm, e camadas A, B, C, de 0-10 cm, 10-20 cm, e 20-40 cm. Nesse sentido, observou-se que a maior parte dos impactos afeta o solo, além desses, houve impactos nos recursos hídricos e no ar da região. Recomendam-se implantação de bosques ou cortinas vegetais, para recuperação do solo e atenuação dos impactos da supressão vegetal (erosão); as lavras exauridas podem servir como tanques para piscicultura. $\mathrm{Na}$ análise dos parâmetros, atenção se dá para o Carbono e a relação Carbono x Nitrogênio, os quais evidenciaram a degradação do solo devido a baixa capacidade de decomposição da matéria orgânicao no horizonte superficiel $(0-10 \mathrm{~cm})$. Portanto, concluiu-se que apesar do segmento cerâmico oferecer emprego e renda para a população, é necessário se atentar para questões ambientais, principalmente no que se refere ao solo do local de extração, de modo a se alcançar um desenvolvimento mais sustentável no ramo.
\end{abstract}

Palavras-chave: Mata ciliar; Matéria prima; Exploração.

\begin{abstract}
Clay is a mineral resulting from the breakdown of rocks that contain feldspar, through the action of weathering. This mineral is of great importance for the civil construction segment, as bricks and tiles are obtained through it. The intensive
\end{abstract}


use and exploitation of these natural resources has significantly degraded the environment, and generates environmental impacts such as, for example, alteration of the landscape, formation of lakes, alteration of topography, alteration in the structure and biology of the soil, etc. The municipality of São Miguel do Guamá is a ceramic production hub, and its extraction areas already have several negative impacts, such as siltation of river beds, formation of lakes, changes in topography, among others. Thus, this research aims to make an Environmental Impact Assessment Matrix - MAIA, list the mitigation measures of these impacts, and make a chemical analysis of the $\mathrm{pH}$, Phosphorus, Potassium, Nitrogen, Carbon x Nitrogen, and Organic Carbon parameters; (Yellow Latosol) at the study site. Samples were collected using three trenches, $50 \times 50 \mathrm{~cm}$ thick, and layers A, B, C, 0-10 cm, 10-20 cm, and 20-40 cm. In this sense, it was observed that most of the impacts affect the soil, in addition to these, there were impacts on water and air resources in the region. It is recommended to install woods or vegetation curtains, for soil recovery and mitigation of the impacts of vegetation suppression (erosion); depleted fields can serve as ponds for fish farming. In the analysis of the parameters, attention is given to the Carbon and the Carbon $x$ Nitrogen ratio, which evidenced soil degradation due to the low capacity of organic matter decomposition in the superficial horizon $(0-10 \mathrm{~cm})$. Therefore, it was concluded that although the ceramic segment offers employment and income to the population, it is necessary to pay attention to environmental issues, especially with regard to the soil of the extraction site, in order to achieve a more sustainable development in the field.

Keywords: Riparian forest; Raw material; Exploration.

\section{Resumen}

La arcilla es un mineral resultante de la descomposición de rocas que contienen feldespato, mediante la acción de la intemperie. Este mineral es de gran importancia para el segmento de la construcción civil, ya que a través de él se obtienen ladrillos y tejas. El uso y explotación intensiva de estos recursos naturales ha degradado significativamente el medio ambiente, y genera impactos ambientales como, por ejemplo, alteración del paisaje, formación de lagos, alteración de la topografía, alteración de la estructura y biología del suelo, etc. El municipio de São Miguel do Guamá es un polo de producción de cerámica, y sus áreas de extracción ya tienen varios impactos negativos, como sedimentación de lechos de ríos, formación de lagos, cambios en la topografía, entre otros. Así, esta investigación tiene como objetivo realizar una Matriz de Evaluación de Impacto Ambiental - MAIA, enumerar las medidas de mitigación de estos impactos y realizar un análisis químico de los parámetros de $\mathrm{pH}$, Fósforo, Potasio, Nitrógeno, Carbono x Nitrógeno y Carbono Orgánico; (Latosol amarillo) en el sitio del estudio. Las muestras se recolectaron utilizando tres zanjas de 50x50 cm de espesor y las capas A, B, C, 0-10 cm, 10-20 cm y 20-40 cm. En este sentido, se observó que la mayoría de los impactos afectan al suelo, además de estos, hubo impactos en los recursos hídricos y aéreos de la región. Se recomienda instalar maderas o cortinas de vegetación, para la recuperación del suelo y mitigación de los impactos de la supresión de la vegetación (erosión); los campos agotados pueden servir como estanques para la piscicultura. En el análisis de los parámetros se presta atención a la relación Carbono y Carbono x Nitrógeno, que evidenciaron degradación del suelo debido a la baja capacidad de descomposición de materia orgánica en el horizonte superficial (0$10 \mathrm{~cm}$ ). Por ello, se concluyó que si bien el segmento cerámico ofrece empleo e ingresos a la población, es necesario prestar atención a los aspectos ambientales, especialmente en lo que se refiere al suelo del sitio de extracción, con el fin de lograr un desarrollo más sustentable en el campo.

Palabras clave: Bosque de ribera; Materia prima; Exploración.

\section{Introdução}

A argila é um mineral do grupo dos filossilicatos proveniente da desagregação de rochas que contém feldspato, através da ação do intemperismo (Nociti, 2011). E no Brasil tem sua produção para confecção de cerâmicas desde 1968, adquirida através do aumento da temperatura em fornos atingindo em volta de $1200^{\circ} \mathrm{C}$, tornando - se um produto de acentuada firmeza mecânica, e resistência a ambientes alcalinos e ácidos (Paiva, 2017).

Os utensílios provenientes de material cerâmico são utilizados desde a antiguidade por diversos tipos de pessoas e com várias finalidades econômicas e simbólicas (Schmitt; Avello, 2013). A atividade no ramo da cerâmica, tem apresentado uma grande expansão no setor econômico bem como, uma acentuada importância para o desenvolvimento urbano (Holanda; Silva, 2011).

Umas das atividades econômicas no munícipio de São Miguel do Guamá é a fabricação de telhas e tijolos para região, que contribui para seu desenvolvimento urbano, o seu produto primordial para a realização de sua produção é a argila, um recurso natural não renovável (Racanelli et al., 2020).

A exploração mineira da argila para atender a indústria cerâmica da região de São Miguel do Guamá, no estado do Pará provoca impactos ambientais. O processo inclui a supressão vegetal, remoção da camada superficial do solo rico em nutrientes 
além da escavação da área. Como consequência ocasiona a exposição do solo, contribuindo para a perda de nutrientes, redução da diversidade biológica, instabilidade hidrológica, alteração fisico - quimica, consequentemente processos erosivos, impactando provocando limitações no uso do solo como exemplo a agricultura (Silva et al., 2013).

Com base no exposto tornam-se essenciais estudos sobre os impactos ocasionados no meio ambiente devido a retirada de recursos naturais, como a argila, para a fabricação de tijolo na indústria cerâmica.

\subsection{Objetivos}

\subsubsection{Geral}

Identificar os impactos ambientais ocasionados pela extração da argila no solo.

\subsubsection{Específicos}

- Identificar os impactos ambientais ocasionados em decorrência do processo de extração da argila no solo.

- Propor medidas de mitigação dos impactos.

- Fazer a análise química do solo.

\subsection{Revisão a Literatura}

\subsubsection{Qualidade do solo}

O solo é uma rede complexa que permite troca entre matéria e energia com o meio, devido a relação entre subsistemas que o compõe (macro e microrganismos). Além disso, abriga resíduos orgânicos de origem animal e vegetal mortos. Diante disso, essa matéria orgânica (MO) torna-se nutriente para o solo, logo, o nível de fertilidade está atrelado a quantidade de MO no solo, constituído por níveis chamados de horizontais (O, A, B, C, D), que diferem em cor, composição, e textura, (Almeida; Sanches, 2014).

Em relação aos solos amazônicos, estima-se que a classificação para a região são as seguintes: Argissolos, Latossolos, Solos de Várzea, Terra Preta de Índio, Solos de Igapó por último Nitossolo, segundo o Sistema Brasileiro de Classificação de Solos da Embrapa (2013).

Os altos índices pluviométricos na região facilitam o processo de lixiviação de alguns nutrientes do solo como o fosforo (P), nitrogênio (N), e potássio (K) (Valladares, Batistella, Pereira, 2010). Todavia, estes três elementos químicos, devem estar associados as seguintes características: saturação por alumínio alta; baixa Capacidade de Troca Catiônica (CTC), além da pobreza em macro e micronutrientes, por isso, os solos amazônicos apresentam valores elevados de potencial Hidrogeniônico (pH) ácido ou levemente ácido (4, 5 a 5,5) (Moline; Coutinho, 2015).

Outro elemento químico muito importante no solo, é o carbono (C), que pode apresentar-se sob a denominação de “orgânico" (Corg e/ou COT.). Esse tipo de carbono é um dos meios para avaliar e estudar o solo via quantidade e fração dele no solo $( \pm 58 \%)$. Mas, as ações antrópicas podem determinar a degradação do solo, e influi diretamente no teor de Nitrogênio $(\mathrm{N})$, pois o (COT) é a principal fonte deste nutriente (Hickmann; Costa, 2012).

Consequentemente, a junção de todos esses elementos e substâncias, permite ao solo, o fornecimento de inúmeros serviços ecossistêmicos essenciais ao bem-estar humano como: provisão (plantio de alimento); suporte (nutrientes); e regulação (sequestro de carbono). Com efeito, o COT, também serve como indicadores dos serviços ambientais do solo (Loss et al, 2011).

\subsubsection{Usos do solo}

Os solos são recursos naturais mais utilizados por todas as formas vivas do planeta, considerados estratégicos devido aos seus serviços ecossistêmicos (provisão, regulação). Todavia, este também tem papel fundamental para o ser socioambiental, 
no que diz respeito a economia, como por exemplo na agropecuária, usos para extração de recursos, mineração e habitação (Pinheiro, 2015).

$\mathrm{Na}$ agropecuária, é por meio do uso do solo que animais (e.g. bovinos) vivem, e onde também é produzido seu alimento, através do plantio de espécies de capins: Elefante capiaçu (Pennisetum purpureum Schum); Tifton (Cynodon spp); Mombaça (Megathyrsus maximus). Consequentemente, o solo possui caráter fundamental para produção agrícola (Bonini, et al., 2016).

Há também utilização para habitação, quando é realizado o uso e ocupação do solo, especificamente para moradia para interesse social de um povo. Desse modo, deve-se haver planejamento urbano com preocupação ambiental, onde possa ser evidenciado a utilização deste recurso natural para o desenvolvimento local com foco na proteção do mesmo, e diminuição dos impactos no ecossistema (Honda, et al.,2015).

Quanto extração mineral, consiste na exploração do solo, e formação de lavras para extração de materiais geralmente encontrados no subsolo, onde por sua vez estão localizados os minerais. Alguns destes, agregam valor econômico no mercado, como por exemplo, ouro, cobre, argila. Todavia a retirada desses materiais, em alguns casos provocam danos quase que irreversíveis ao meio ambiente, principalmente no solo (Mechi; Sanches, 2010).

\subsubsection{Processo de extração da argila}

Nestas perspectivas, pode-se dizer que o processo de extração de argila se dá basicamente em três fases: A primeira diz respeito a prospecção para descoberta de local que se encontra este bem mineral de interesse econômico, isto se dá por meio de levantamentos geológicos seguido de georreferenciamento da área em questão. Já a segunda fase, compreende estudos de viabilidade econômica, por outro lado, na terceira é incorporada a parte estrutural da indústria de apoio como por exemplo, abertura de estradas de acesso, e todo maquinário necessário (Gama; Mello; Gama, 2019).

A partir da terceira fase a exploração mineração de argila é feita a céu aberto com maquinário pesado, em períodos de estiagem tempos de baixa precipitação para melhor se obter acesso ao local de extração. Além disso, os depósitos de sedimentos argilosos estão localizados próximos a superfície e cobertos por uma camada de solo de pouca espessura (Lima, 2017).

Ainda neste contexto, uma das técnicas mais utilizadas no processo de extração consiste na lavra, trata-se da quebra mecânica das camadas em escavações feitas em tiras semicirculares com auxílio de máquinas pesadas como: escavadeira, retroescavadeira, caçamba basculante. Este método, é conceituado segundo o Decreto Lei nº. 227/67 (CÓDICO DE MINERAÇÃO) que dispõe de ações e processos indispensáveis para exploração em escala industrial até a etapa de beneficiamento. (Freitas et al, 2019).

\subsubsection{Danos ocasionados pela extração de argila}

A exploração e eventual processo de extração mineral da argila, ocorre trazendo problemas graves ao meio ambiente, principalmente no que diz respeito as características do solo, uma vez que, para que ocorra todas estas etapas são necessários supressão da vegetação local em todos os extratos florestais. Em consequência disso, há perda da capacidade de resiliência do terreno (Faria, et al; 2020).

Além disso, devido ao revolvimento da área para retirada da flora local, acontece o que se chama de revolvimento do solo, com efeito, é retirado os horizontes A e B, pois a matéria prima(argila), encontra-se aproximado ao C. Com isto, acontece perda de horizonte orgânico superficial, e deficiência de biodiversidade dos organismos associados à microbiota e mesofauna do solo. Além da degradação do solo, provocada pela retirada da vegetação existente no local, implicando na perda da biota existente, afloramento do lençol freático e ainda mudanças no microclima local. (Everton et al., 2013).

Seguindo estes preceitos, acontece compactação do solo e aumento na taxa de escoamento superficial e formação de crateras proveniente da retirada de argilas. Ademais, pode-se dar início ao processo de desertificação, processo pelo qual ocorre 
perda de nutrientes de forma excessiva e o solo não consegue retornar as suas características originais, ou próximas desta. O termo desertificação é utilizado a mais de 40 anos e define uma série de processos de degradação ecológica, em particular, a transformação gradual de florestas tropicais em ecossistemas mais secos (Verstraete, 1986; Neto et al., 2018).

Por ser um recurso natural não renovável a exploração da argila deve ser realizada fundamentalmente de forma adequada para a conservação do solo, e desta forma, manter os teores de matéria orgânica no solo adequado, o equilíbrio químico, a drenagem e a estabilidade dos fatores de intemperismo (Rodrigues, 2017).

\subsubsection{Ações de recuperação}

A área degradada pela retirada da argila necessita ser recuperada afim de se minimizar os danos causados, e para tal o primeiro passo a ser dado é por meio do zoneamento do local e a caracterização do solo utilizado, isto facilita a escolha das medidas cabíveis para a reposição do ambiente modificado pela ação antrópica (Silva et al., 2017).

Neste contexto, é necessário a reposição de espécies florestas que consigam se desenvolver no ambiente com terreno parcialmente degradado. Para isso, é de fundamental importância que seja feito manejo adequado deste solo, o horizonte superficial (O), precisa ser reposto mesmo que em uma pequena camada, este deve ser retirado de áreas afastadas do local da mineração (Ferreira et al., 2010).

A partir disso, realiza-se nesta etapa de preparo da área para plantio, cercar o terreno para que não tenha invasão de animais de pequeno e grande porte evitando o pisoamento, além de proteger contra incêndios florestais e queimadas. Isto deve ser efetuado, 30 a 40 dias antes da revegetação, além disso, essas medidas servem para o início da descompactação e aumento da taxa de infiltração do solo (Silva, 2010).

Ademais, a vegetação pode ser feita por semeadura, todavia o plantio de mudas é mais efetivo, porém, o custo de serviço é maior. Outro além desses, a utilização do método de enleivamento ou leiva, apresenta resultado satisfatório com maior rapidez. Desse modo, a condução dessas técnicas de maneira equilibrada e conjunta aumenta as chances de se recuperar a resiliência do terreno (COFA, 2006). No processo de recuperação de área degrada a utilização de espécies de vegetais, como leguminosas, tende a melhorar o atributo local que sofreu alteração, através da decomposição de serapilheira (Silva et al., 2012).

Para que estas medidas ocorram com maior exatidão, é preciso que está área seja monitorada para evitar quaisquer empecilhos como por exemplo, controle de pragas e ervas invasoras. Além disso, está mensurando constantemente os nutrientes do solo, para saber se este, possui capacidade de retomar suas características próximas as originais (Silva; Campagna; LIPPNissinen, 2018).

\subsection{6 Área de estudo: Município de São Miguel}

O território guamaense foi colonizado por volta do século XVII por meio das grandes navegações realizadas pelos colonos portugueses na Amazônia, uma das suas atividades econômicas está voltada para produção de telhas e tijolos, o crescimento dessa atividade cerâmica no município de São Miguel do Guamá está ligado a fatores internos e externos (Cordowil; Nahum, 2011).

De acordo com Pena et al.(2020), aproximadamente 77 \% das cerâmicas são cadrastadas formalmente, com 39 milheiros sendo produzido por mês, incluindo telhas e tijolos. Ainda o mesmo autor, afirma não haver nem uma forma de controle dos resíduos gerados, e estes são descartados de qualquer forma na natureza, como a céu aberto.

Atualmente o município de São Miguel do Guamá é o maior polo ceramista, localizado no nordeste paraense, visto como um grande produtor de cerâmica vermelha, no que se refere a argila principal fonte de matéria prima desse setor. Além disso, o município apresenta sobretudo, um solo do tipo: Latossolo Amarelo, textura média (Cardoso, et al., 2019). 
O município de São Miguel é caracterizado como uma localidade de temperatura adequada e solo propicio para agricultura (Ribeiro et al., 2021).

A atividade cerâmica é responsável por inúmeros impactos na região, devido a exploração excessiva dos recursos naturais e poluição dos recursos hídricos, podendo causar erosão em suas margens, contaminação do lençol freático em virtude de escavações, retirada da vegetação próximo ao rio, que ocorre em consequência da retirada da argila para produção cerâmica, ocasionando impacto na fauna e flora (Cardoso et al., 2019).

De acordo com o IBGE, a população estimada do município de São Miguel do Guamá no ano de 2019 foi aproximadamente 58.986 pessoas, sua densidade demográfica é de 46,4 habitantes por Km2, situada na região norte, apresenta um clima mesotérmico e úmido, as suas coordenadas geográficas de latitude $01^{\circ} 37^{\prime} 36^{\prime}$ ' ao sul, longitude $47^{\circ} 29^{\prime} 00^{\prime \prime}$ a oeste e altitude de 10 m com uma área que se estende por 1094,8 Km2 (Figura 1).

Figura 1 - Mapa de localização do município de São Miguel.

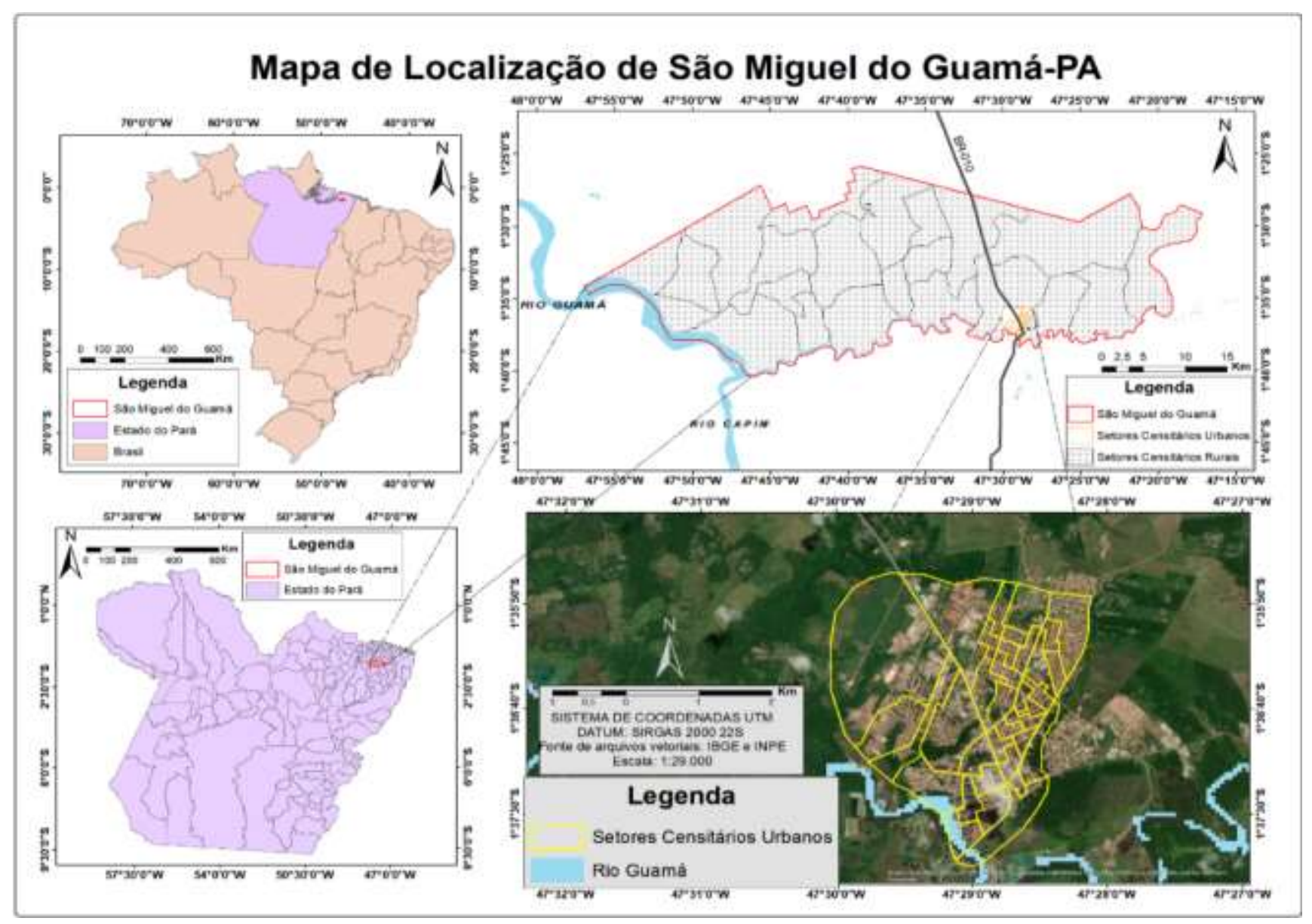

Fonte: Autores (2021).

O Rio Guamá é o mais importante do Município, servindo de limite natural, ao sul, com os municípios de Irituia, São Domingos do Capim e Bujaru (IBGE, 2016). O clima do Município é do tipo mesotérmico e úmido. A temperatura média anual é elevada, em torno de $25^{\circ} \mathrm{C}$. O período mais quente apresenta médias mensais em torno de $25,5^{\circ} \mathrm{C}$. Seu regime pluviométrico fica, geralmente, próximo a $2.250 \mathrm{~mm} /$ ano. As chuvas não se distribuem igualmente durante o ano, sendo de janeiro a junho sua maior concentração (cerca de 80\%), implicando grandes excedentes hídricos e (SMG, 2021). 


\subsubsection{Caracterização da área de estudo}

O trabalho foi realizado em uma área de extração de argila no Município de São Miguel do Guamá, com a escolha de apenas uma cerâmica que serviu como objeto de estudo. O local de coleta do material foi georreferenciado através da tomada de dados de coordenadas geográficas (latitude, longitude e altitude), e encontra-se ao lado de uma cratera de extração, a qual, no período de coleta, encontrava-se ativa. A área está sem cobertura vegetal, e já foi bastante compactada devido ao transito de caçambas e tratores os quais trabalham na extração de matéria prima cerâmica (Figura 2). Vale ressaltar que a área utilizada para extração de argila, no municipio de São Miguel do Guamá-Pá, também foi utilizada para atividades de pisicultura.

Figura 2 - Área da extração onde as trincheiras foram abertas.

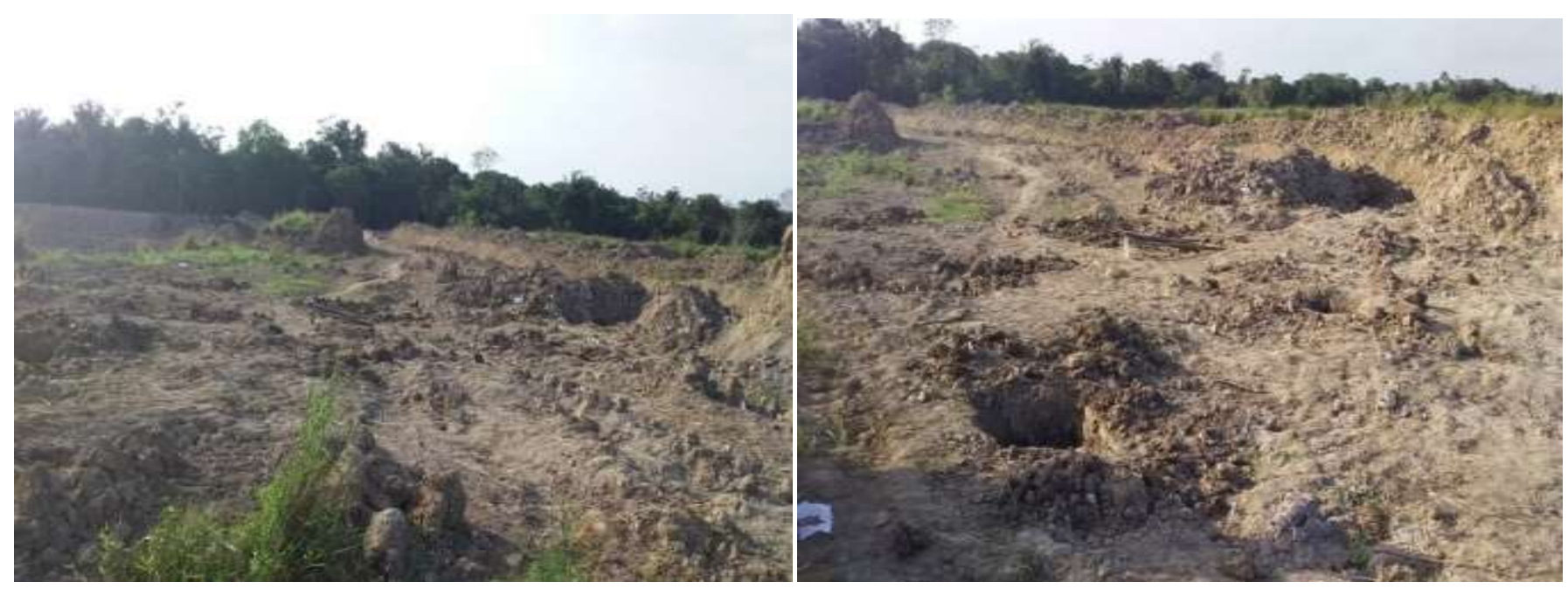

Fonte: Autores (2021).

Os solos do Município são apresentados, sobretudo, pelo Latossolo Amarelo, textura média; Concrecionários Lateríticos indiscriminados ditróficos, textura indiscriminada; Areia Quartzosa distrófico, textura indiscriminada, e hidromórfica indiscriminados (Santos, 2016):

Na região onde ocorre o Latossolo Amarelo o solo é formado dominantemente a partir das Formações Barreiras e Alter do Chão, em relevo plano e ondulado, sob cobertura vegetal tipicamente de floresta densa. É um solo distrófico, profundo, bastante envelhecido, apresentando baixo conteúdo de carbono orgânico, baixa relação com argila e altas saturações em alumínio. Apresenta cores variando de alaranjado escuro no horizonte "A" a amarelo nos horizontes inferiores.

O tipo Concrecionário Laterítico representa solos argilosos a argilo-arenosos medianamente profundos, constituídos por uma mistura de partículas minerais finas e concreções de arenito ferruginoso. Na Amazônia são dominantemente originados a partir de rochas pré-cambrianas, ressaltando-se relevo plano e ondulado, sob cobertura vegetal dominante de floresta densa. Areia Quartzosa representa solos de textura arenosa, com menos de $15 \%$ de argila, sendo essencialmente quartzosas. São formados a partir de sedimentos arenosos predominantemente do quaternário encontrados em relevo dominantemente plano

De acordo com o Mapa de Solos do Brasil (EMBRAPA, 2020), o solo encontrado na região possui predominância de Latossolo Amarelo, tipo +LA31, e segundo Falesi et al. (1967), dos $1.337 \mathrm{~km}^{2}$ do município, aproximadamente 1200 km² são cobertos por este solo. 


\section{Metodologia}

A pesquisa realizada é quanti-qualitativa, com enfoque descritivo das situações observadas e registrada da maneira como ocorrem e as etapas da pesquisa são descritas no fluxograma (Figura 3).

Figura 3 - Fluxograma de procedimentos.

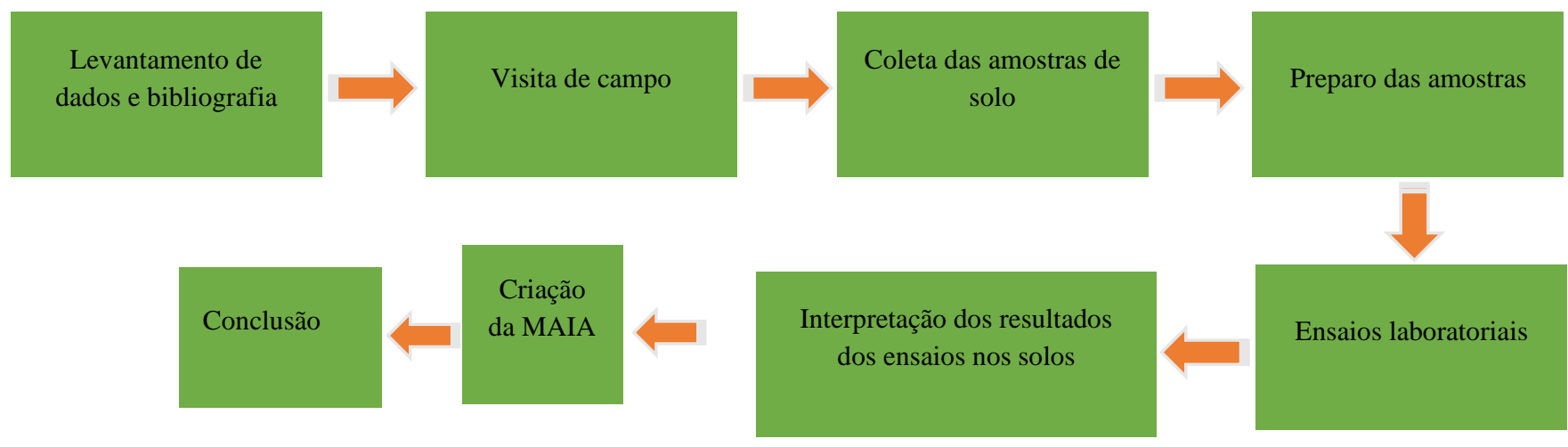

Fonte: Autores (2021).

A pesquisa consistira em um levantamento de campo realizado conforme a metodologia seguida por Pereira; Ruivo (2018), onde a coleta de amostra de solo foi realizada utilizando-se três trincheiras, com espessura de 50x50 cm, e camadas A, B, e C, de 0-10 cm, 10-20 cm, e 20-40 cm, respectivamente, para retirada da argila (Figura 4).

Figura 4 - Mapa de localização da região de extração de argila.
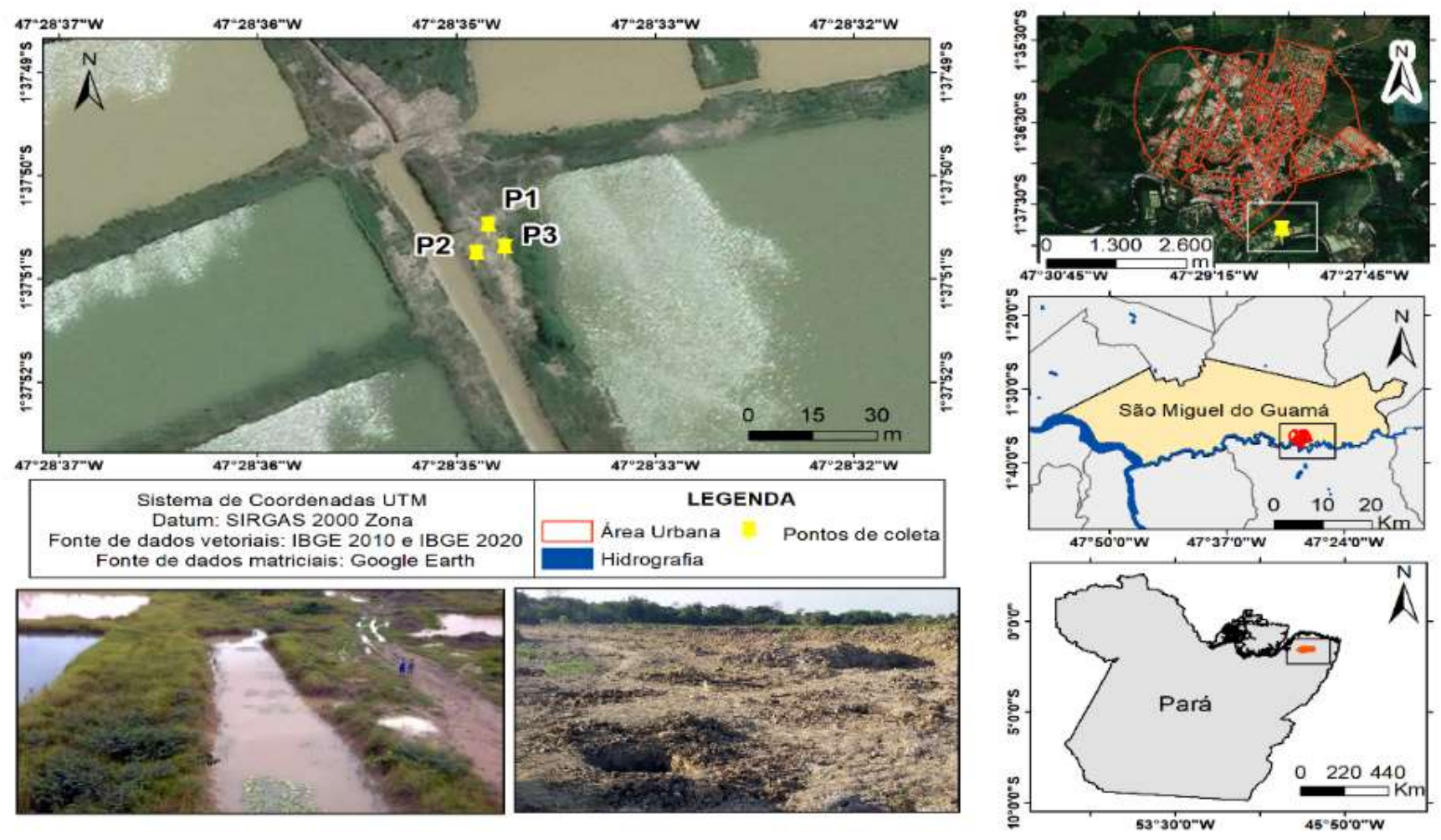

Fonte: Autores (2021). 
O preparo das amostras foi feito de acordo com o Manual de Métodos de Análise de Solo da Embrapa (2017). Depois de preparado, o solo foi enviado ao Laboratório de Análises Agroambientais Pro-Solos, localizado no município Capitão-Poço, para realizar as análises fisico-químicas das amostras.

Os parâmetros analisados no presente trabalho foram escolhidos com base na resposta do solo frente a degradação, conforme sugere Vezzani; Mielniczuk (2009). Nesse sentido, foram selecionadas algumas relações de pH, fósforo, potássio, nitrogênio, relação carbono x nitrogênio, e carbono orgânico.

\subsection{Avaliação de Impactos Ambientais e Mitigação dos Impactos}

Conforme Pereira, et al (2014), a Matriz de Avaliação Impactos Ambientais - MAIA é um artifício que visa identificar os aspectos e avaliar os impactos decorrentes de certas atividades. De acordo com o autor, a matriz demonstra a avaliação e valoração de impactos ambientais e o potencial impactante do processo.

O método utilizado para a Avaliação de Impactos Amientais, teve como base a elaboração de uma MAIA (Matriz de Impacto Ambiental) através da observação in locu. A matriz utilizada foi baseada na pesquisa de Cruz et al. (2019), para a análises de parâmetros natureza, temporalidade, escala, grau de importância, duração, magnitude, reversibilidade, influência, valor, classificação e nível de priorização.

Segundo Walter e Anello (2012), medidas mitigadoras são exigências de investimento na prevenção do uso do meio ambiente e fazem parte do licenciamento ambiental, conforme previsto na Resolução CONAMA 01/1986. Nesse sentido, foi criado uma tabela com as medidas mitigadoras de cada impacto ambiental elencado na MAIA.

\section{Resultados e Discussão}

\subsection{Avaliação de impactos ambientais}

Após a visita in locu, realizou-se a AIA que culminou na classificação dos impactos segundo seu nível de priorização. Dessa forma, observou-se que a maior parte dos impactos afeta o solo e o ar, além desses, há impactos nos recursos hídricos da região (Quadro 1). 
Quadro 1 - Impactos ambientais.

\begin{tabular}{|c|c|c|c|c|c|c|c|c|c|c|c|c|}
\hline \multicolumn{2}{|c|}{$\begin{array}{c}\text { IDENTIFICAÇÃO DE ASPECTOS } \\
\text { E IMPACTOS }\end{array}$} & \multicolumn{11}{|c|}{ AVALIAÇÃO } \\
\hline ASPECTO & IMPACTO & 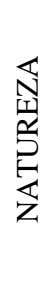 & 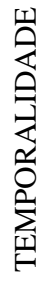 & 岕 & 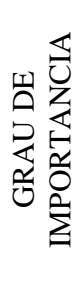 & 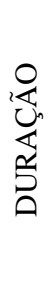 & 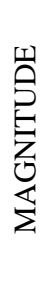 & 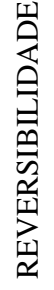 & 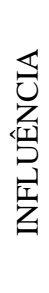 & $\begin{array}{l}\text { 告 } \\
\frac{1}{2} \\
>\end{array}$ & 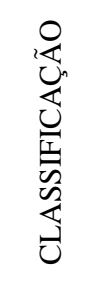 & 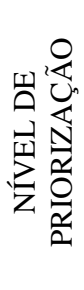 \\
\hline \multirow[t]{3}{*}{$\begin{array}{l}\text { Supressão } \\
\text { Vegetal }\end{array}$} & $\begin{array}{l}\text { Redução da } \\
\text { biodiversidade por } \\
\text { retirada de } \\
\text { vegetação }\end{array}$ & - & $\operatorname{Pr}$ & 2 & 3 & 3 & 3 & $\operatorname{Re}$ & In & 18 & Médio & II \\
\hline & $\begin{array}{l}\text { Perda de nutrientes } \\
\text { e matéria orgânica }\end{array}$ & - & $\operatorname{Pr}$ & 2 & 3 & 3 & 3 & $\operatorname{Re}$ & Di & 18 & Médio & II \\
\hline & Processos erosivos & - & $\operatorname{Pr}$ & 1 & 3 & 2 & 2 & $\operatorname{Re}$ & Di & 6 & Médio & III \\
\hline \multirow[t]{2}{*}{$\begin{array}{l}\text { Extração } \\
\text { Mineral }\end{array}$} & $\begin{array}{c}\text { Modificação da } \\
\text { paisagem }\end{array}$ & - & $\operatorname{Pr}$ & 2 & 2 & 3 & 3 & $\operatorname{Re}$ & Di & 12 & Médio & II \\
\hline & $\begin{array}{l}\text { Compactação do } \\
\text { solo }\end{array}$ & - & $\operatorname{Pr}$ & 2 & 3 & 3 & 2 & $\operatorname{Re}$ & Di & 18 & Forte & II \\
\hline $\begin{array}{c}\text { Emissão gasosa } \\
\text { advinda dos } \\
\text { veículos }\end{array}$ & $\begin{array}{c}\text { Alteração da } \\
\text { Qualidade do Ar }\end{array}$ & - & $\operatorname{Pr}$ & 2 & 1 & 2 & 2 & $\operatorname{Re}$ & Di & 4 & Fraco & I \\
\hline $\begin{array}{l}\text { Implantação de } \\
\text { lagoas de } \\
\text { psicultura } \\
\end{array}$ & $\begin{array}{c}\text { Formação de } \\
\text { Lagoas artificiais } \\
\text { para psicultura }\end{array}$ & + & $\operatorname{Pr}$ & 1 & 2 & 3 & 3 & $\operatorname{Re}$ & Di & 6 & Médio & I \\
\hline $\begin{array}{c}\text { Emissão de } \\
\text { Material } \\
\text { Particulado } \\
\end{array}$ & $\begin{array}{l}\text { Alteração da } \\
\text { qualidade do ar }\end{array}$ & - & $\operatorname{Pr}$ & 2 & 1 & 2 & 2 & $\operatorname{Re}$ & Di & 4 & Fraco & II \\
\hline
\end{tabular}

Natureza - Impacto Positivo (+)/ Impacto Negativo (-); Temporalidade - Presente (Pr)/ Passado (Ps)/ Futuro (F); Escala - Pontual (1)/ Local (2)/ Regional (3); Grau de Importância - Fraca (1)/ Média (2)/ Forte(3); Duração Momentânea (1)/ Temporária (2)/ Permanente (3); Magnitude - Eventual (1)/ Sazonal (2)/ Permanente (3); Reversibilidade - Reversível (Re)/ Irreversível (Ir); Influência - Direta (Di)/ Indireta (In); Valor - Escala x Grau de Importância x Duração; Classificação - Valor + magnitude: Fraco (1 a 7)/ Médio (8 a 17)/ Forte (18 a 30); Nível de Priorização - Baixo (I) / Moderado(II)/ Alto (III).

Fonte: Adaptado de Mila et al. (2018).

Através desse estudo foi possível notar as alterações no ambiente devido à retirada da argila, o primeiro impacto observado foi a perda da camada superficial, o qual foi classificado como Médio. Ademais, Cardoso et al. (2019), afirma que a retirada dessa camada se dá sem um mínimo de estudos e sem as devidas licenças, o que agrava os impactos.

Ressalta-se que também foram observadas alterações na estrutura e na biologia do solo, consequências da erosão, que é comum em áreas de lavra. Tais impactos foram classificados como "Médio". Nesse sentido, Mechi; Sanches (2010) e Paz et al. (2015), também encontrou locais de extração de argila propícios ao assoreamento e erosão, tendo em vista, a descaracterização do ambiente como foi possível analisar, fato que corrobora com a atual pesquisa.

Observou-se também o impacto no solo causado pelo trânsito de máquinas pesadas na área, que acarreta na compactação do solo, o qual foi classificado como "Médio". Nesse sentido, de acordo com Portela (2014), o solo possui uma conformação estrutural, capaz de propiciar adequado suprimento de ar, água e nutrientes, mas quando se tem o rompimento do arranjo estrutural, ocorre uma alteração das condições de aeração e umidade, o que pode gerar degradação. 
Outro impacto observado, foi a redução da biodiversidade devido à retirada da vegetação, o qual foi classificado como "Médio". Isso ocorre devido ao afugentamento de animais, consequência do desmatamento necessário para abertura das lavras. Segundo Penno (2010), ainda que não existe mata nativa na área diretamente afetada, há de se considerar as coberturas vegetais nativas vizinhas ao empreendimento, as quais abrigam uma infinidade de exemplares da flora e da fauna.

A formação de lagoas artificiais em cavas abandonadas é bastante comum em regiões produtores de argila, e também foi observada no presente trabalho, sendo classificada como de "Médio" impacto (Figura 5).

Figura 5 - Formação de lagoas em locais de extração abandonados

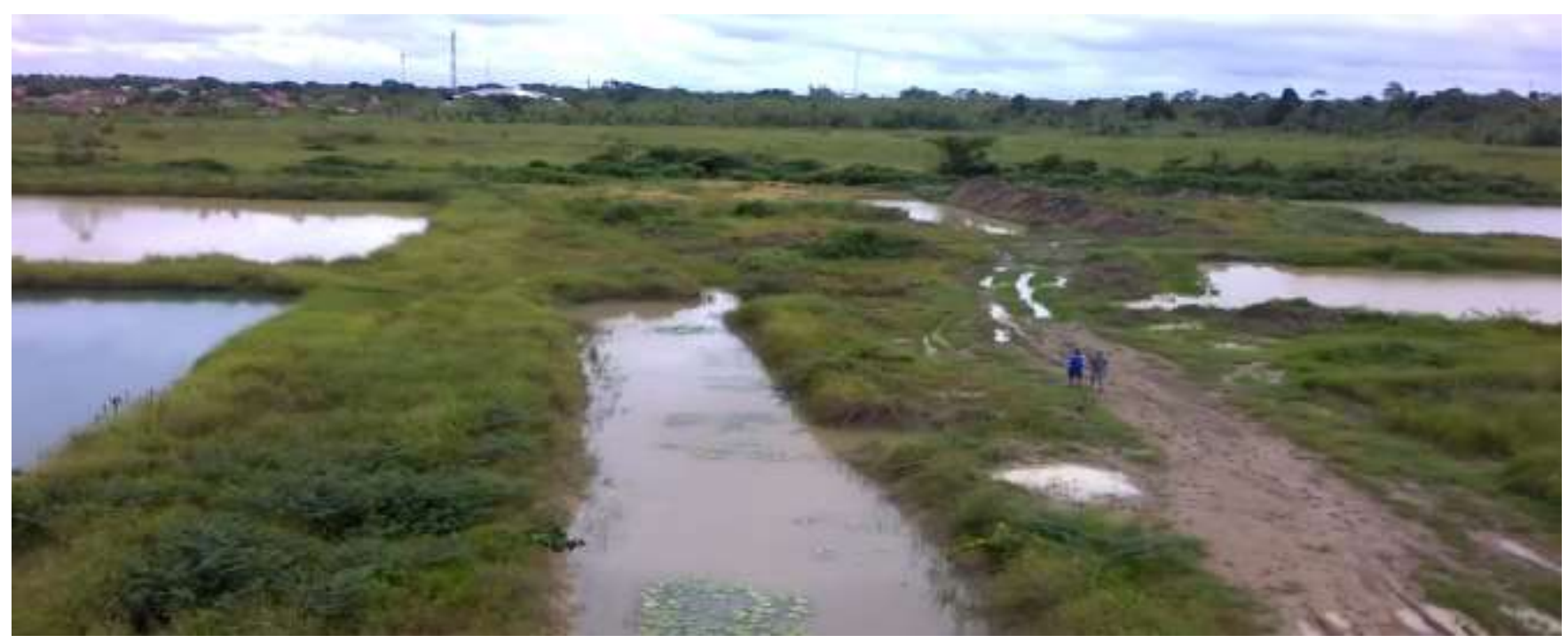

Fonte: Autores (2021).

Segundo Mechi; Sanches (2010), muitas cavas que são abertas em várzeas resultam na formação de lagoas, que apesar da utilização, acabam abandonadas e em processo de eutrofização (que consiste na perda de oxigênio dissolvido devido ao consumo pelas bactérias, as quais se propagam no corpo hídrico devido ao acúmulo de nutrientes), o que gera odores desagradáveis e perda na qualidade da água. Quando esta situação se repete ao longo da mesma várzea, há um adensamento de lagoas e alterações significativas do ambiente original devido aos impactos cumulativos.

Em cavas de extração de argila localizadas em áreas de várzea, é comum ocorrer o rebaixamento do lençol freático, além da retirada da mata ciliar, o que prejudica o curso hídrico, gerando diminuição da disponibilidade hídrica, impacto este classificado como "Fraco" devido a área de extração não ser muito extensa.

Nesse sentido, pode-se afirmar que a consequência ambiental para grandes áreas de exploração, não se restringe apenas a área afetada, mas coloca em perigo outras áreas em uma dimensão mais abrangente. Ademais, Cardoso et al. (2019), que realizou pesquisa também no município de São Miguel, afirma que a atividade de extração de argila provoca várias formas de degradação no entorno do Rio Guamá, como a formação de lagoas artificiais, mudanças topográficas, desmatamentos, queimadas dentre outros.

Observou-se também a alteração da qualidade do ar sob dois aspectos: através da emissão de gases advindos da queima do diesel e a emissão de material particulado, o qual classificou-se como "Fraco". Este impacto afeta não só as pessoas que estão trabalhando sem EPI, mas também os moradores do entorno da obra, pois, as plumas de vento transportam o ar para vários quilômetros do seu local de origem. Este fato é corrobora com as pesquisas de Manfredini (2003); Cardoso et al. (2019). 


\subsection{Medidas de Mitigação dos impactos}

Após realizada a MAIA, criou-se as estratégias para a mitigação de cada um dos impactos, de acordo com o que alguns autores recomendam (Quadro 2).

Quadro 2 - Estratégias para mitigação dos impactos elencados na MAIA.

\begin{tabular}{|l|l|}
\hline \multicolumn{1}{|c|}{ Impactos } & \multicolumn{1}{c|}{ Estratégia de mitigação } \\
\hline Perda da camada superficial do solo & $\begin{array}{l}\text { Implantação de Bosques na área já minerada, } \\
\text { Armazenamento do solo fértil; (Manfredini, 2003; Paz, } \\
\text { 2015; Penno, 2010) }\end{array}$ \\
\hline Alteração na estrutura e na biologia do solo & $\begin{array}{l}\text { Implantação de Bosques na área já minerada } \\
\text { (Manfredine 2003; Paz 2015); Armazenamento do solo } \\
\text { fértil; (Manfredini, 2003) }\end{array}$ \\
\hline Compactação do solo & $\begin{array}{l}\text { Implantação de Bosques na área já minerada } \\
\text { (Manfredini, 2003) }\end{array}$ \\
\hline Redução da biodiversidade por retirada de vegetação & $\begin{array}{l}\text { Implantação de Bosques na área já minerada } \\
\text { (Manfredini, 2003; Paz, 2015; Penno, 2010) }\end{array}$ \\
\hline Formação de Lagoas artificiais & $\begin{array}{l}\text { Criação de tanques de aquicultura (Paz, 2015) } \\
\text { Diminuição da disponibilidade hídrica }\end{array}$ \\
$\begin{array}{l}\text { Controle técnico na profundidade das cavas (; Penno, } \\
\text { 2010); Implantação de Bosques na área já minerada } \\
\text { (Manfredini, 2003) }\end{array}$ \\
\hline $\begin{array}{l}\text { Alteração da Qualidade do Ar pela queima de } \\
\text { combustível dos veículos }\end{array}$ & $\begin{array}{l}\text { Implantação de Cortina Vegetal (Manfredini, 2003); } \\
\text { Manutenção periódica de máquinas e equipamentos } \\
\text { (Penno, 2010) }\end{array}$ \\
\hline $\begin{array}{l}\text { Alteração da Qualidade do Ar pela emissão de partículas } \\
\text { de poeira }\end{array}$ & $\begin{array}{l}\text { Implantação de Cortina Vegetal (Manfredini, 2003); } \\
\text { aspersão de água sobre as vias não-pavimentadas } \\
\text { situadas no principal acesso a obra e no interior do } \\
\text { empreendimento (Penno, 2010). }\end{array}$ \\
\hline
\end{tabular}

Fonte: Autores (2021).

Observa-se através do quadro, que muitos autores recomendam a implantação de bosques ou cortinas vegetais, para mitigar a maioria dos impactos. Ademais, nenhuma dessas medidas foram observadas no local onde o presente estudo ocorreu.

Vale ressaltar que os itens acima citados devem constar no Plano de Controle Ambiental - PCA da Licença de Operação da mineradora, no entanto, a maioria não possui nenhum item que caracterize o seu Sistema de Gestão Ambiental, o que impossibilita a implantação de tais medidas, bem como a própria fiscalização do poder público.

Sobre este fato, Santos (2016), afirma que nos municípios de São Miguel do Guamá e região, das 46 olarias instaladas, apenas 28 (60\%) possuem áreas de lavra devidamente legalizadas no DNPM, já Pena et al. (2020), afirma que no município de São Miguel do Guamá, em média, 77\% das cerâmicas são cadastradas formalmente.

\subsection{Utilização da Piscicultura como destinação futura da área}

Durante a visita in locu, foi observado que algumas lavras abandonadas estavam, ou já tinham sido usadas para fins de produção de peixes. Do ponto de vista ambiental, esta forma de recuperação de área é de extrema importância, pois, alia preservação ambiental (impede a abertura de novos tanques) com ganhos financeiros (através do consumo ou da venda do pescado.

Nesse sentido, de acordo com Paz et al. (2015) Quando a atividade de extração de argila é finalizada na jazida é comum a reabilitação da área para fins de piscicultura, vale ressaltar que esta atividade deve ser "devidamente orientada para garantir o sustento das famílias locais, evitando assim a ocorrências de vetores de doenças, principalmente, no período chuvoso". 
No caso de São Miguel do Guamá, esta medida é facilitada em áreas que se encontram mais próximas dos rios (Guamá e Irituia) visto que a água pode ser acumulada naturalmente, através da implantação de um sistema de drenagem entre as cavas e o rio. Assim, não haveria a diminuição da lamina d"água durante os períodos de estiagem. Este procedimento permitiria que as espécies já adaptadas ao rio tivessem livre acesso as lagoas, e lá constituíssem o seu novo habitat. Em conjunto poderia ser introduzidos viveiros para a criação de patos, gansos etc (Santos, 2016).

\subsection{Análise laboral}

$\mathrm{Na}$ análise de $\mathrm{pH}$ os resultados obtidos das amostras de cada trincheira foram considerados com um nível moderado de acidez, e a camada 0-10 apresentou-se mais ácido que as demais (Tabela 1).

Tabela 1 - Relação pH em água.

\begin{tabular}{c|c|c|c|c}
$\begin{array}{c}\text { Profundidade } \\
(\mathbf{c m})\end{array}$ & Amostra 1 & Amostra 2 & Amostra 3 & Média \\
\hline $0-10$ & 5,8 & 6,5 & 6,2 & 6,17 \\
\hline $10-20$ & 6,5 & 5,9 & 6,7 & 6,37 \\
\hline $20-40$ & 6,1 & 6,5 & 6,5 & 6,37
\end{tabular}

Fonte: Autores (2021).

O solo apresentou-se mais ácido na Amostra 1, camada 0-10 ( $\mathrm{pH}=5,8)$; e o valor mais alto na Amostra $3(\mathrm{pH}=6,7)$. $\mathrm{O}$ valor mais baixo de $\mathrm{pH}$ encontrado na camada superficial pode estar relacionado com a ausência de cobertura vegetal, pois, a mesma fornece bases que atuam neutralizando a acidez.

Ademais, Silva et al. (2006), em pesquisa realizada no município de Marituba, Pará, encontrou valores de pH semelhantes no horizonte mais superficial (Ap), porém, mais ácidos, para diferentes tipos de usos de terra: Floresta Secundária $=\mathrm{pH} 5$; Cultura de Cacau $=\mathrm{pH} 4,8 ;$ derruba e Queima $=\mathrm{pH} 5,7$; Pastagem Abandonada $=\mathrm{pH} 4,4$.

Quanto ao elemento Fósforo notou-se a tendência de diminuição na concentração conforme o avanço da profundidade. Além disso, denota-se menor concentração na camada 20-40, com valor médio igual a 1,13 mg/kg (Tabela 2).

Tabela 2 - Fósforo.

\begin{tabular}{c|c|c|c|c|c}
$\begin{array}{c}\text { Profundidade } \\
(\mathbf{c m})\end{array}$ & Unidade & Amostra 1 & Amostra 2 & Amostra 3 & Média \\
\hline \multirow{2nnnyy}{0}{-10} & \multirow{3}{*}{$\mathrm{mg} \cdot \mathrm{kg}^{1}$} & 0,55 & 2,28 & 1,53 & 1,45333 \\
\cline { 3 - 6 } $10-20$ & 1,86 & 0,98 & 2,9 & 1,91333 \\
\cline { 3 - 5 } $20-40$ & & 1,01 & 0,75 & 1,63 & 1,13000
\end{tabular}

Fonte: Autores (2021).

Nesse sentido, a deficiência do fósforo na camada mais profunda é esperado devido ao nutriente apresentar pouca mobilidade no solo, o que faz sua concentração ser maior na camada mais superficial, e os baixos valores refletem o empobrecimento do solo, onde, segundo Pereira; Ruivo (2018), o elemento Fósforo apresenta-se deficiente em quase $90 \%$ da região do nordeste do Pará.

Segundo Marques et al. (2004), o elemento Fósforo reduziu sua concentração quando se aumentou a profundidade em todos os perfis analisados de um Latossolo Amarelo em um plantio agroflorestal. Os autores afirmaram que esse comportamento pode ser atribuído aos maiores teores de matéria orgânica em superfície e adubações sucessivas, refletindo o efeito cumulativo da aplicação de adubos. 
No caso do elemento Potássio, houve uma variação baixa de acordo com a profundidade, e o mesmo não apresentou um comportamento uniforme (Tabela 3 ).

Tabela 3 - Potássio.

\begin{tabular}{c|c|c|c|c|c}
$\begin{array}{c}\text { Profundidade } \\
(\mathbf{c m})\end{array}$ & Unidade & Amostra 1 & Amostra 2 & Amostra 3 & Média \\
\hline 0 0-10 & \multirow{2}{*}{ mg.kg1 } & 0,13 & 0,17 & 0,11 & 0,13 \\
\cline { 3 - 5 } & & 0,13 & 0,21 & 0,2 & 0,18 \\
\cline { 3 - 5 } $10-20$ & 0,21 & 0,15 & 0,17 & 0,17
\end{tabular}

Fonte: Autores (2021).

De acordo com as médias, o elemento Potássio apresentou valor mais reduzido $(0,13 \mathrm{mg} / \mathrm{kg})$ na camada superficial $(0$ $10 \mathrm{~cm})$ e valor mais acentuado $(0,18 \mathrm{mg} / \mathrm{kg})$ na camada mediana $(10-20 \mathrm{~cm})$, caracterizando uma desuniformização nos resultados. Estes valores são relativamente baixos, e corroboram com a pesquisa de Pereira; Ruivo (2018), que afirma que solos de Terra Firme na Amazônia geralmente apresentam baixa fertilidade química, com baixa disponibilidade de nutrientes essenciais disponíveis, além da ciclagem desses nutrientes ocorrem através do caráter fechado, predominantemente.

Segundo Marques et al. (2004), que realizou pesquisa em Latossolo Amarelo coberto por sistema agroflorestal na região de Manaus, Amazonas, o elemento potássio apresentou maior concentração no horizonte mais superficial, variando de 4,6 mg.dm ${ }^{3}(0-0,12 \mathrm{~m})$ a $0,8 \mathrm{mg} \cdot \mathrm{dm}^{3}(1-1,5 \mathrm{~m})$, resultados estes que diferem da atual pesquisa, principalmente devido ao tipo de uso do solo.

O elemento Nitrogênio apresentou tendência de redução em todas as amostras até a camada 10-20, na qual ele reduziu na Amostra 1, permaneceu inalterado na Amostra 2, e aumentou na Amostra 3 (Tabela 4).

Tabela 4 - Nitrogênio Total.

\begin{tabular}{|c|c|c|c|c|c|}
\hline $\begin{array}{l}\text { Profundidade } \\
(\mathrm{cm})\end{array}$ & Unidade & Amostra 1 & Amostra 2 & Amostra 3 & Média \\
\hline $0-10$ & \multirow{3}{*}{ g.kg1 } & 5,8 & 1,12 & 0,96 & 2,62 \\
\hline $10-20$ & & 0,42 & 1 & 0,81 & 0,74 \\
\hline $20-40$ & & 0,19 & 1,01 & 1,12 & 0,77 \\
\hline
\end{tabular}

Fonte: Autores (2021).

O parâmetro Nitrogênio mostrou-se com maior concentração na camada mais superficial (0-10) devido à influência orgânica, natural desta camada. Seu valor máximo foi igual a 5,8 g/kg na Amostra $1(0-10 \mathrm{~cm})$, e o valor mais reduzido foi igual a $0,19 \mathrm{~g} / \mathrm{kg}$, na mesma amostra, no horizonte $20-40 \mathrm{~cm}$. Estes valores reduzidos nas camadas mais profundas, de acordo com Silva et al. (2006), são comumente encontrados em Latossolos na região da Bacia Amazônica, onde a maior parte do nutriente encontra-se estocado nos primeiros $20 \mathrm{~cm}$ de solo.

Falesi et al. (1967), em pesquisa realizada no Município de São Miguel, também constatou que os valores de nitrogênio diminuem com a profundidade, apresentando uma variação de 0,2 a 0,33 g/100g no horizonte A, e de 0,03 a 0,05 g/100g no horizonte B.

Já a relação Carbono/Nitrogênio variação no seu resultado, e uniformização nas três camadas da Amostra 3 (Tabela 5). 
Tabela 5 - Relação Carbono/Nitrogênio.

\begin{tabular}{c|c|c|c|c}
$\begin{array}{c}\text { Profundidade } \\
(\mathbf{c m})\end{array}$ & Amostra 1 & Amostra 2 & Amostra 3 & Média \\
\hline $0-10$ & $8 / 1$ & $12 / 1$ & $11 / 1$ & $10,33 / 1$ \\
\hline $10-20$ & $4 / 1$ & $11 / 1$ & $11 / 1$ & $8,66 / 1$ \\
\hline $20-40$ & $10 / 1$ & $12 / 1$ & $11 / 1$ & $11 / 1$
\end{tabular}

Fonte: Autores (2021).

A Amostra 1 apresentou a maior variação entre as camadas, e de maneira geral, o parâmetro apresentou os maiores valores nas camadas mais profundas $(20-40 \mathrm{~cm})$, com média igual a 11/1 nessas camadas. Vale ressaltar que as Amostras 2 e 3 , obtiveram valores iguais nas camadas superficiais $(0-10 \mathrm{~cm})$, e nas camadas profundas $(20-40 \mathrm{~cm})$, o que evidencia a baixa capacidade de decomposição de matéria orgânica na camada superficial dessas amostras, pois, quanto mais baixo o valor deste parâmetro, maior será o processo de decomposição da matéria orgânica.

A atual pesquisa corrobora com os resultados de Falesi et al (1967), os quais afirmam que a relação Carbono/Nitrogênio aumenta com a profundidade e oscila entre 7,8 a 12,7 no horizonte A e 9,8 a 12,4 no horizonte B, em um Latossolo Amarelo. Além disso, Moraes et al. (2015), afirmam que os menores valores desse parâmetro foram encontrados na camada superficial (0 - $5 \mathrm{~cm}$ ) do Latossolo Amarelo de uma Floresta Explorada, em comparação com o solo de um Plantio Convencional e Plantio Direto, devido ao material orgânico advindo da floresta favorecer a decomposição nesta camada.

No que tange ao elemento Carbono Orgânico, o mesmo comportou-se de forma decrescente no horizonte do solo, conforme se aumentava a profundidade da trincheira (Tabela 6).

Tabela 6 - Carbono Orgânico.

\begin{tabular}{c|c|c|c|c|c}
$\begin{array}{c}\text { Profundidade } \\
(\mathbf{c m})\end{array}$ & Unidade & Amostra 1 & Amostra 2 & Amostra 3 & Média \\
\cline { 1 - 4 } $0-10$ & \multirow{3}{*}{$\%$} & 0,79 & 1,29 & 1,1 & 1,06 \\
\cline { 1 - 3 } & \multirow{2}{*}{$\%-20$} & 0,48 & 1,14 & 0,93 & 0,85 \\
\cline { 1 - 3 } & & 0,21 & 1,16 & 1,28 & 0,88
\end{tabular}

Fonte: Autores (2021).

A maior concentração do Carbono Orgânico foi encontrada na camada superficial da Amostra 2, (1,29 \%; camada 0-10 $\mathrm{cm})$, já o menor foi encontrado no horizonte 20-40 cm da Amostra 1 (0,21\%). Dessa forma, os valores elevados encontrados na camada superficial relacionam-se ao conteúdo de matéria orgânica, que é, em regra, superior na camada superficial, e decresce com o aprofundamento do horizonte.

Esta relação corrobora com as pesquisas de Marques et al. (2004), e Silva et al (2006), os quais também observaram o mesmo comportamento em Latossolos Amarelos no Centro de Pesquisas da EMBRAPA Oriental, Amazonas, e na região Paragominense, respectivamente.

Por conseguinte, o valor baixo, encontrado no horizonte 0-10 cm da Amostra 1 (0,79\%), indica perda de MO e empobrecimento da camada superficial, o que pode ser causa da supressão vegetal na área.

\section{Conclusão}

O aumento da demanda por telhas e tijolos na construção civil, transformou o município de São Miguel do Guamá em um polo do segmento ceramista, gerando renda aos trabalhadores do ramo, porém, criando diversos passivos ambientais. Ainda que a maioria dos empreendimentos de extração de argila seja licenciado, a fiscalização ainda é incipiente, e as medidas de 
recuperação ainda não alcançaram um patamar de desenvolvimento sustentável, o que pode ser notado pela quantidade de cavas abandonados na região, pois, poucas são usadas como tanques de piscicultura.

Dessa forma, através da Matriz de Avaliação de Impactos Ambientais, observou-se que todos os impactos são de caráter reversível caso seja aplicada alguma medida de mitigação, e que o principal meio afetado é o solo, devido à erosão. Ressalta-se que os rios próximos aos locais de extração são impactados pelo assoreamento, o que prejudica o modo de vida dos habitantes locais, que possuem ampla relação com este recurso.

Ademais, foi possível elencar as medidas de recuperação relacionadas a cada impacto descrito na MAIA, ressaltando a utilização das lavras como tanques de piscicultura, o que já ocorre no local, e é de fundamental importância do ponto de vista de recuperação devido ao fato de combinar a medida de mitigação com ganho financeiro ou alimentar. Essas medidas, de acordo com as regras para o licenciamento ambiental, devem estar contidas no Plano de Controle Ambiental - PCA, que é um documento exigido pelas Secretarias de Meio Ambiente, porém, devido ao déficit de funcionários nessas secretarias, a fiscalização é praticamente inviabilizada. Isso é uma realidade em muitos municípios no Brasil.

As análises laboratoriais certificaram o que foi levantado na MAIA, pois, através através de parâmetros, principalmente o Carbono Orgânico, concluiu-se que a área está de fato degradada, com o horizonte orgânico do solo pobre em nutrientes, e menos ácido que o normal, para um Latossolo Amarelo. Outro parâmetro que demonstra degradação é a relação carbono $\mathrm{x}$ nitrogênio, a qual mostrou-se alta no horizonte superficial, evidenciando a baixa capacidade de decomposição presente nas amostras. Dessa forma, compromete-se a resiliência do solo, pois, o retorno do horizonte orgânico é inviabilizado pela baixa capacidade de decomposição do material orgânico.

Portanto, todos os objetivos foram alcançados. Cita-se a importância de efetuar mais estudos na região para que a atividade possa se tornar cada vez menos predatória devido à necessidade que o município possui de manter o segmento gerando emprego e renda. Ademais, estes estudos podem estar voltados às medidas de atenuação e mitigação dos impactos, além da utilização futura da área, criando uma logística reversa que dê utilidade para áreas de lavra, impedindo, dessa forma, o seu abandono.

\section{Referências}

Almeida, R. F., \& Sanches, B. C. (2014). Disponibilidade de carbono orgânico nos solos do cerrado brasileiro. Scientia Agraria Paranaensis, 13(4), 259-264.

Bonini, C. D. S. B., Lupatini, G. C., Andrighetto, C., Mateus, G. P., Heinrichs, R., Aranha, A. S., ... \& Meirelles, G. C. (2016). Produção de forragem e atributos químicos e físicos do solo em sistemas integrados de produção agropecuária. Pesquisa agropecuária brasileira, 51, $1695-1698$.

Cardoso, E. P., Oliveira, W. S., \& de Moraes, S. S. Impactos Ambientais Ocasinado Pela Extração Industrial De Argila No Município De São Miguel Do GuamáPa Impactos Ambientales Octado Por Extracción Industrial De Argilla Em El Municipio De São Miguel Do Guamá-Pa Environmental Impacts Ocaused By Industrial Clay Extraction. In: Congresso Internacional das Ciências Agrárias, 4. Anais. Teresina: Theresina Hall

Cordovil, G. V., \& Nahum, J. S. (2011). Indústrias cerâmicas e desenvolvimento territorial em São Miguel do Guamá-PA. ENTRE-LUGAR, 2 (4), 65-93.

Grant, C., Loch, R., McCaffrey, N., Anstee, S., \& Doley, D. (2016). Mine rehabilitation: leading practice sustainable development program for the mining industry.

Cruz, M. C. S; Santos, C. O. R.; Lima, N. S.; Brito, R. P. (2019) Estudo dos Impactos ambientais em uma indústria cerâmica no Município de Paragominas, Pará. In: Simpósio de Estudos e Pesquisas em Ciências Ambientais na Amazônia, 8, Anais. Belém: UEPA

MG. (1967). Decreto-Lei n . 227, de 28 de fevereiro de 1967 (Código de Minas). Dá nova redação ao Decreto-lei nº 1.985, de 29 de janeiro de 1940. Braília: DOU.

Santos Everton, N., Morales, C., \& da Silva, A. A. A. Identificacao De Impactos Ambientais Gerados Pela Producao De Cerâmica Vermelha No Entorno Da Reserva Extrativista Marinha Caeté-Taperaçu Do Município De Braganca-PA. In: Congresso de Brasileiro de Gestão Ambiental, 4, Anais. Salvador: IBEAS.

EMBRAPA, Empresa Brasileira de Agropecuária - Solos (2021). Mapa de Solos do Brasil. 2020.

EMBRAPA, Empresa Brasileira de Agropecuária - Solos (2013). Sistema brasileiro de classificação de solos. 3.

EMBRAPA, Empresa Brasileira de Agropecuária (2017). Manual de Métodos de Análise de Solos. (3a ed.), Embrapa, 
Faria, A. G. V., de Carvalho, P. S., Bergamo, J. A., Ocanha, M., \& Pereira, P. S. (2020). Argila como tema contextualizador e crítico: uma proposta para o ensino de Química. Revista Científica Multidisciplinar Brilliant Mind, 1(01), 69-84.

Falesi, Í. C., Vieira, L. S., dos Santos, W. H. P., \& Oliveira Filho, J. P. S. (1967). Levantamento de reconhecimento dos solos da região Bragantina, Estado do Pará. Pesquisa Agropecuária Brasileira, 2(1), 1-63

Ferreira, W. C., Botelho, S. A., Davide, A. C., Faria, J. M. R., \& Ferreira, D. F. (2010). Regeneração natural como indicador de recuperação de área degradada a jusante da usina hidrelétrica de Camargos, MG. Revista Árvore, 34, 651-660.

Freitas, C. M. D., Barcellos, C., Asmus, C. I. R. F., Silva, M. A. D., \& Xavier, D. R. (2019). Da Samarco em Mariana à Vale em Brumadinho: desastres em barragens de mineração e Saúde Coletiva. Cadernos de Saúde Pública, 35.

Gama, M. F. (2019). O Passivos Ambientais Oriundos Da Extração De Argila Na Amazonia: Mesorregião Do Sudeste Paraense. Contemporânea (ISSN 26752107), 1(1)

Holanda, R. M., \& da Silva, B. B. (2012). Cerâmica Vermelha-Desperdício na Construção Versus Recurso Natural Não Renovável: Estudo de Caso nos Municípios de Paudalho/PE e Recife/PE (Red Ceramic-Construction Waste Versus Non-Renewable Natural Resource: A Case Study in Paudalho-PE and...). Revista Brasileira de Geografia Física, 4(4), 872-890.

Honda, S. C. D. A. L., Vieira, M. D. C., Albano, M. P., \& Maria, Y. R. (2015). Planejamento ambiental e ocupação do solo urbano em Presidente Prudente (SP). urbe. Revista Brasileira de Gestão Urbana, 7, 62-73.

Hickmann, C., \& Costa, L. M. D. (2012). Estoque de carbono no solo e agregados em Argissolo sob diferentes manejos de longa duração. Revista Brasileira de Engenharia Agrícola e Ambiental, 16(10), 1055-1061.

IBGE, C. (2019). Instituto Brasileiro de Geografia e Estatística-IBGE.

Lima, L. B. (2017). Caracterização da extração mineral de argila no município de Caxias-Ma. Revista Ciência \& Saberes-UniFacema, 2(4), 297-302.

Loss, A., Pereira, M. G., Giácomo, S. G., Perin, A., \& Anjos, L. H. C. D. (2011). Agregação, carbono e nitrogênio em agregados do solo sob plantio direto com integração lavoura-pecuária. Pesquisa Agropecuária Brasileira, 46, 1269-1276.

Maia, F. D. S. (2012). Avaliação de massas cerâmicas, processamento e propriedades dos produtos de cerâmica vermelha do pólo cerâmico de campos dos Goytacazes. Universidade Estadual do Norte Fluminense-Campos dos goytacazes-RJ-agosto-2012.

ManfredinI, C. (2003). Impactos ocasionados pela indústria da cerâmica vermelha no Rio Grande do Sul. Dissertação (Mestrado em Engenharia Civil) Universidade Federal do Rio Grande do Sul, Porto Alegre.

Marques, J. D. D. O., Libardi, P. L., Teixeira, W. G., \& Reis, A. M. (2004). Estudo de parâmetros físicos, químicos e hídricos de um Latossolo Amarelo, na região Amazônica. Acta amazônica, 34, 145-154.

Mechi, A., \& Sanches, D. L. (2010). Impactos ambientais da mineração no Estado de São Paulo. Estudos avançados, 24, 209-220.

Veiga Moline, E. F., \& Coutinho, E. L. M. (2015). Atributos químicos de solos da Amazônia Ocidental após sucessão da mata nativa em áreas de cultivo. Revista de Ciências Agrárias Amazonian Journal of Agricultural and Environmental Sciences, 58(1), 14-20.

Moraes, A. R. A.; Filho, L. F. F. M.; Gomes, M. S.; Gomes, M. F. G.; Miranda, L. S.; Segtowich, A. C. (2015). Teores de Carbono, Nitrogênio e Relação C:N em solos cultivados com soja em sistema plantio direto e convencional em Paragominas, Pará.

Neto, D. V. R., Monteiro, F. M., de Oliveira Ferreira, P. S., \& dos Santos, E. G. Atividade Ceramista Em Parelhas/Rn: Impactos Ambientais Adversos E Possíveis Medidas Mitigadoras.

Nociti, D. M. (2011). Aproveitamento de rejeitos oriundos da extração de minério de ferro na fabricação de cerâmicas vermelhas.

Paiva, D. C. A. C. (2017). Efeito da concentração de fósforo na degradação aeróbia do glifosato em reator de leito fixo.

Paz, Y. M., Gouveia, R. L., Silva, J. F., \& de Holanda, R. M. (2015). A atividade de extração de argila e a relação homem-natureza| The clay mining activity and the man-nature relationship. Revista Geama, 261-274.

Pena, S. D., Neto, B. B. P., \& Gomes, L. G. (2020). Análise percentual da utilização de fosfogesso em protótipos prismáticos de uma indústria de cerâmica vermelha. Brazilian Journal of Development, 6(9), 70352-70373.

Pereira, A.; Ruivo, L. (2018). Fertilidade e Fauna edáfica do solo sob reflorestamento. Belém: Novas Edições Acadêmicas.

Penno, M. C. (2010). Impactos e controles ambientais na mineração de argila: um estudo de caso no município de Santa Rosa de Lima/SC.

Pereira, D. H., Ferreira, L. F., de Souza, M. M., \& Ferreira, D. D. M. (2014). Matriz de aspectos e impactos ambientais como ferramenta de evidenciação de contingências ambientais. Revista de Gestão Ambiental e Sustentabilidade, 3(2), 74-91.

Pinheiro, A. C. (2015). Valor económico do solo: perspectivas pública e privada. Revista de Ciências Agrárias, 38(4), 612-620.

Portela, M. O. B., \& Gomes, J. M. A. (2015). Extração de argila no bairro Olarias (Em Teresina-Pi) e Suas Implicações Socioeconômica e Ambiental.

Racanelli, L. D. A., Cândido, V. S., Souza, J. A. D. S., \& Cardoso, D. N. (2020). Caracterização e Estudo das Propriedades Físicas, Químicas e Mecânicas das Argilas Cauliníticas da Região Nordeste do Estado do Pará. Matéria (Rio de Janeiro), 25.

Ribeiro, L. O., da Silva Luz1, A. L., Andreta, H. K., \& Donicht, A. P. A Cultura Do Açaí No Município De São Miguel Do Guamá, Pará 
Research, Society and Development, v. 10, n. 10, e576101019030, 2021

(CC BY 4.0) | ISSN 2525-3409 | DOI: http://dx.doi.org/10.33448/rsd-v10i10.19030

Rodrigues, T. C. (2017). Uso da terra na área de influência direta de extração de argila no municipio de jataí-go. Monografia (Graduação em Geografia) Universidade Federal de Goiás, Jataí.

São Miguel do Guamá, Prefeitura Municipal (2021). Coordenadoria Municipal de Proteção e Defesa Civil. Relatório Diagnóstico para Ações de Prevenção.

Faria, A. G. V., de Carvalho, P. S., Bergamo, J. A., Ocanha, M., \& Pereira, P. S. (2020). Argila como tema contextualizador e crítico: uma proposta para o ensino de Química. Revista Científica Multidisciplinar Brilliant Mind, 1(01), 69-84.

Santos, D. T (2016). Caracterização Socioambiental, Econômica da Extração de Argila no município de São Miguel do Guamá-PA. 2016. Trabalho de Conclusão de Curso (Bacharelado em Geologia) - Universidade Federal do Pará, Belém.

Schmitt, D. V., \& Avello, A. S. (2013). Por uma história moldada na argila: O uso de oficina de cerâmica para conhecer diferentes culturas. Revista LatinoAmericana de História-UNISINOS, 2(6), 495-506.

Silva, I. R., Pereir, L. C. C., \& da Costa, R. M. (2009). Exploração de Argila em Fazendinha e os Impactos Socioambientais (Amazônia, Brasil). Revista de Gestão Costeira Integrada-Journal of Integrated Coastal Zone Management, 9(2), 85-90.

Silva, H. R, Mello, A. H.; Oliveira, G. F.; Santos, N. R.; Gama, M. F. F. (2013). Estudo de degradação dos solos e ambiente na área de extração de argila da cerâmica Nova Era- Marabá-PA. In: Congresso Brasileiro de Ciência do Solo, 34. Anais. Florianópolis.

Silva, G. R. D., Silva Jr, M. L. D., \& Melo, V. S. D. (2006). Efeitos de diferentes usos da terra sobre as características químicas de um latossolo amarelo do Estado do Pará. Acta Amazonica, 36, 151-157

Silva, R. G., \& da Silva, V. P. (2017). Produção mais limpa: contributos teórico-práticos para a sustentabilidade da cerâmica vermelha. Cerâmica, 63, 494-507.

Silva, C. F. D., Simões-Araújo, J. L., Silva, E. M. R. D., Pereira, M. G., Freitas, M. S. M., Saggin, O. J., \& Martins, M. A. (2012). Fungos micorrízicos arbusculares e proteína do solo relacionada à glomalina em área degradada por extração de argila e revegetada com eucalipto e acácia. Ciência Florestal, 22 , 749-761.

Silva, G.J. (2010). Agência Embrapa de Informação Tecnológica: Manejo do Solo. Empresa Brasileira de Pesquisa Agropecuária (EMBRAPA).

Silva, I. A., Campagna, A. R., \& LIPP-Nissinen, K. H. (2018). Recuperação de áreas degradadas por mineração: uma revisão de métodos recomendados para garimpos. Pesquisas em Geociências, 45(3), 0691.

Valladares, G. S., Batistella, M., \& Pereira, M. G. (2011). Alterações ocorridas pelo manejo em Latossolo, Rondônia, Amazônia brasileira. Bragantia, 70, 63637.

Verstraete, M. M. (1986). Defining desertification: a review. Climatic Change, 9(1), 5-18.

Vezzani, F. M., \& Mielniczuk, J. (2009). Uma visão sobre qualidade do solo. Revista Brasileira de Ciência do Solo, 33, 743-755.

Walter, T., \& de Anello, L. D. F. S. (2012). A Educação Ambiental Enquanto Medida Mitigadora E Compensatória: uma reflexão sobre os conceitos intrínsecos na relação com o Licenciamento Ambiental de Petróleo e Gás tendo a pesca artesanal como contexto. Ambiente \& Educação, 17(1), 73-98. 